\title{
Influence of Fiber Volume and Fiber Length on Thermal and Flexural Properties of a Hybrid Natural Polymer Composite Prepared with Banana Stem, Pineapple Leaf, and S-Glass
}

\author{
K. B. Prakash, ${ }^{1}$ Yahya Ali Fageehi, ${ }^{2}$ Rajasekaran Saminathan, ${ }^{2}$ P. Manoj Kumar $\mathbb{D}^{3}{ }^{3}$ \\ S. Saravanakumar, ${ }^{4}$ Ram Subbiah, ${ }^{5}$ B. Arulmurugan, ${ }^{3}$ and S Rajkumar $\mathbb{D}^{6}$ \\ ${ }^{1}$ Department of Mechanical Engineering, Bannari Amman Institute of Technology, Sathyamangalam 638401, Tamil Nadu, India \\ ${ }^{2}$ Department of Mechanical Engineering, College of Engineering, Jazan University, Jazan, Saudi Arabia \\ ${ }^{3}$ Department of Mechanical Engineering, KPR Institute of Engineering and Technology, Coimbatore 641407, Tamil Nadu, India \\ ${ }^{4}$ Department of Mechanical Engineering, M. Kumarasamy College of Engineering, Karur 639113, Tamil Nadu, India \\ ${ }^{5}$ Department of Mechanical Engineering, Gokaraju Rangaraju Institute of Engineering and Technology, Hyderabad 500090, \\ Telangana, India \\ ${ }^{6}$ Department of Mechanical Engineering, Faculty of Manufacturing, Institute of Technolog, Hawassa University, \\ Hawassa, Ethiopia
}

Correspondence should be addressed to S Rajkumar; rajkumar@hu.edu.et

Received 17 August 2021; Revised 17 September 2021; Accepted 18 September 2021; Published 7 October 2021

Academic Editor: Jinyang Xu

Copyright $\odot 2021$ K. B. Prakash et al. This is an open access article distributed under the Creative Commons Attribution License, which permits unrestricted use, distribution, and reproduction in any medium, provided the original work is properly cited.

There is more demand for natural fiber-reinforced composites in the energy sector, and their impact on the environment is almost zero. Natural fiber has plenty of advantages, such as easy recycling and degrading property, low density, and low price. Natural fiber's thermal properties and flexural properties are less than conventional fiber. This work deals with the changes in the thermal properties and mechanical properties of S-glass reinforced with a sodium hydroxide-treated pineapple leaf (PALF) and banana stem fibers. Banana stem and pineapple leaf fibers (PALF) were used at various volume fractions, i.e., $30 \%$, $40 \%$, and $50 \%$, and various fiber lengths of $20 \mathrm{~cm}, 30 \mathrm{~cm}$, and $40 \mathrm{~cm}$ with S-glass, and their effects on the thermal and mechanical properties were studied, and their optimum values were found. It was evidenced that increasing the fiber volume and fiber length enhanced the flexural and thermal properties up to $40 \%$ of the fiber volume, and started to decrease at $50 \%$ of the fiber volume. The fiber length provides an affirmative effect on the flexural properties and a pessimistic effect on the thermal properties. The PALF S-glass combination of $40 \%$ fiber load and $40 \mathrm{~cm}$ fiber length provides maximum flexural strength, flexural modulus, storage modulus, and lowest loss modulus based on hybrid Taguchi grey relational optimization techniques. PALF S-glass hybrid composite has been found to have $7.80 \%, 3.44 \%, 1.17 \%$ higher flexural strength, flexural modulus, and loss modulus, respectively, and $15.74 \%$ lower storage modulus compared to banana S-glass hybrid composite.

\section{Introduction}

Due to the demand for lower dense material and green environment, fiber-reinforced composites (FRCs) have drawn more awareness towards the alternatives to metalreinforced composites. Natural fibers are effectively utilized in polymer matrices as reinforcement [1]. Fillers such as particles or filaments are created with polymers to get items with the most needed mechanical, thermal, and electrical properties. The characteristics of natural composites are primarily subject to their particular fiber characteristics [2]. There are different variables, which influence the properties of the microstructural boundaries, such as fiber radius, length of fiber, fiber spread, fiber direction, loading weight of the fiber, and production method [3]. Natural fibers have more limitations, such as hydrophilic behavior, which leads to decreased adhesive properties [4]. In addition, natural fibers have more attraction to water particles from moisture, 
and they are affected easily by ultraviolet rays, so more variations in their thermal and mechanical properties occur [5]. Hence, to limit these issues, researchers are focusing on natural-fiber-strengthened composites with polymer matrices.

The addition of natural fibers to polymers is referred to as hybrid composites. It overcomes the limitations and enhances the hindering properties of the natural and the polymer composites [6,7]. Gowda et al. [8] worked on various types of natural fibers, i.e., silk, bamboo, kapok, coconut fiber, which were reinforced with polymer matrices and reported that the addition of natural fiber enhances the mechanical and thermal characteristics of the polymer matrices by $6-10 \%$. Similarly, Abdul Karim et al. worked on various natural fibers, such as hemp, coir, and jute, and studied the properties of the mechanical and thermal characteristics of hybrid natural polymer composites and enhanced its properties to 4-8\% [9]. Sheng and Gimbun found that an increment in the fiber volume fraction increases the flexural strength linearly from $4 \%$ to $6 \%$ up to 0.4 fiber fraction [10]. Jain et al. varied the fiber fraction from 0.1 to 0.3 and found that there is increment in tensile strength and flexural strength by $3-8 \%$ [11]. Chollakup et al. used the different fibers and found that PALF and banana fiber provides better mechanical and thermal properties [12]. Shih et al. conducted a study and discovered that the tensile and flexural strengths of PALF and banana fibers are approximately $80 \%$ and $50 \%$ higher, respectively, than the other fibers [13]. Asim et al. deliberated different fiber loadings with PALF and banana fibers resulting in flexural strength increase with an upsurge in fiber loading [14].

Nur et al. [15] investigated the influence of the fiber length and found that an increment in the PALF length intensifies the tensile strength and flexural strength of the composite by $8-12 \%$. Aji et al. varied the fiber length and found that an increase in the fiber length increases the tensile strength and flexural strength by $8-12 \%$ [16]. Luo and Netravali varied the fiber length of the natural composites and found that there were significant effects on the thermal and mechanical properties [17]. Chollakup et al. discovered that the increment in the fiber length provides positive effects on the flexural and thermal properties up to a certain fiber length of $30 \mathrm{~cm}$, after which it shows a counter-effect [18]. Lopattananon et al. varied the fiber length and found that the fiber length increases the loss of mass during the analysis of thermal characteristics [19].

The fiber loading and fiber length discover the drastic changes in the characteristics of the composites, and it creates both positive and negative effects $[13,20,21]$. The improvement was noticed in tensile strength, hardness, and strain modulus with an upsurge in the fiber volume, fiber length, and fiber type, respectively. The fiber fraction, fiber length, fiber type, and fiber treatment process are the significant elements influencing the properties of the composites [22-24]. Hence, it is a significant role being a researcher to study the effects of various compositions of natural fibers, their treatment methods, fiber length, and fiber volume on the mechanical and thermal properties $[25,26]$.
Natural fiber composites retain better thermomechanical and electrical properties if the interfacial bonds between the matrix and fiber are strong enough [27-29]. As of now, there is less data available on natural fiber reinforcement with S-glass polymer matrices; especially, there is no optimized data about the combination, which provides a better result of thermomechanical properties. The novelty of this work is that it pays special attention to determining the optimum mechanical and thermal characteristics of the polymer hybrid composites with various fiber loadings and different fiber lengths of banana stem, PALF, and S-glass.

\section{Materials and Methods}

2.1. Materials. Banana stems and pineapple leaves were taken as fiber materials, and their fiber lengths were chosen as $20 \mathrm{~mm}, 30 \mathrm{~mm}$, and $40 \mathrm{~mm}$. The S-glass fabric was selected as synthetic fiber with $600 \mathrm{gsm}$, and its size was fixed as $30 \mathrm{~cm}$ square. Epoxy resins were used as resins. The properties of materials are given in Table 1 . The pineapple leaf was chemically treated with $6 \%$ sodium hydroxide, and it was immersed in it for 3 hours [30]. The banana leaf was also treated with the same method, and its immersion time was 2 hours. Then, it was dried in the furnace for 24 hours at $60^{\circ} \mathrm{C}$, and it was weighted for the required volume as per equation (1) [19]. Naturally, untreated fibers tend to absorb moisture, which can cause delamination between the fibers and the polymer matrix and seriously affect the strength of the resulting composite material [31]. This is because natural fibers are hydrophilic, so their reinforcing effect can be minimized. Second, the hydrophobicity of the polyurethane matrix in conjunction with the hydrophilic fibers will lead to poor adhesion, phase separation, and limited stress load transfer in the composite foam [32]. Additionally, the presence of certain organic compounds (such as wax and pectin) found on the surface of these fibers can sometimes act as a barrier to destroy the effective interfacial adhesion between the filler and the polymeric matrix [33],

$$
V_{f}=\frac{W_{f} / \rho_{f}}{\left(W_{f} / \rho_{f}\right)+\left(W_{m} / \rho_{m}\right)}
$$

where $V_{f}$ is the volume fraction of fiber (\%), $W_{m}$ and $W_{f}$ are the mass of the matrix and fiber, respectively, and $\rho_{m}$ and $\rho_{f}$ refer to the density of the matrix and fiber, respectively.

The S-glass was kept in the middle layer to avoid stress concentration on a single point [34]. Hence, stresses were transferred to the natural fiber of both the bottom and topsided fibers. As per the ASTM: D790 standard, flexural assessments were carried out.

2.2. Methods. The different sets of hybrid composites were made by the hot compression method as shown in Figure 1. The specimens prepared with different fiber volume fraction and fiber length are labelled as shown in Table 2.

A morphological investigation was accomplished to analyze the presence of interfacial attachment between the fiber and epoxy resin. Sample tests were covered with a skinny layer of gold, proceeded to scan to build the thermal 
TABLe 1: Properties of tested materials.

\begin{tabular}{lcccc}
\hline Properties & Unit & S-glass fiber & Banana fiber & PALF fiber \\
\hline Density $(\rho)$ & $\mathrm{kg} / \mathrm{m}^{3}$ & 2500 & 1350 & 1520 \\
Tensile strength & $\mathrm{MPa}$ & 4570 & 212 & 8 \\
Young's modulus & $\mathrm{GPa}$ & 86 & 2 & 34 \\
Elongation at the failure & - & 2.8 & 2 & 1.6 \\
\hline
\end{tabular}

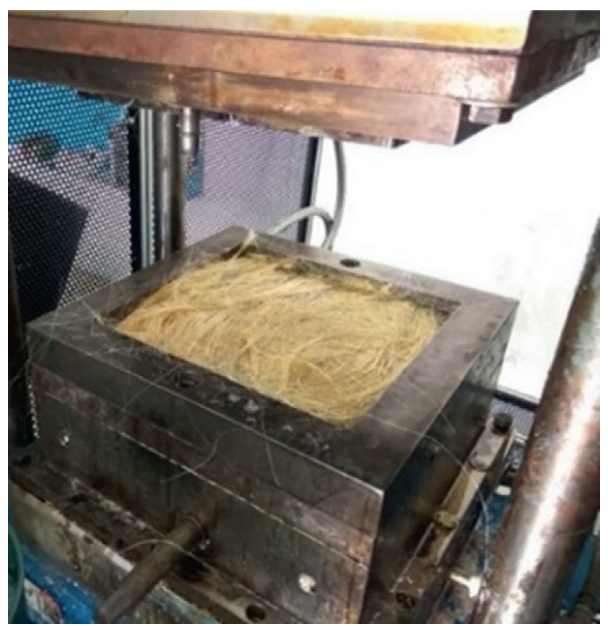

Figure 1: Preparation of samples with a hot compression method.

TABle 2: Prepared samples of the hybrid composite.

\begin{tabular}{|c|c|c|c|c|c|}
\hline Combination & Symbolic representation & S-glass fiber & Banana fiber & PALF fiber & Fiber length \\
\hline S-glass banana PALF & SGBP30 & 1 & 0.15 & 0.15 & 20 \\
\hline S-glass banana PALF & SGBP40 & 1 & 0.20 & 0.20 & 30 \\
\hline S-glass banana PALF & SGBP50 & 1 & 0.25 & 0.25 & 40 \\
\hline $30 \%$ S-glass banana & SGB3020 & 1 & 0.3 & - & 20 \\
\hline $30 \%$ S-glass banana & SGB3030 & 1 & 0.3 & - & 30 \\
\hline $30 \%$ S-glass banana & SGB3040 & 1 & 0.3 & - & 40 \\
\hline $40 \%$ S-glass banana & SGB4020 & 1 & 0.4 & - & 20 \\
\hline $40 \%$ S-glass banana & SGB4030 & 1 & 0.4 & - & 30 \\
\hline $40 \%$ S-glass banana & SGB4040 & 1 & 0.4 & - & 40 \\
\hline $50 \%$ S-glass banana & SGB5020 & 1 & 0.5 & - & 20 \\
\hline $50 \%$ S-glass banana & SGB5030 & 1 & 0.5 & - & 30 \\
\hline $50 \%$ S-glass banana & SGB5040 & 1 & 0.5 & - & 40 \\
\hline $30 \%$ S-glass PALF & SGP3020 & 1 & - & 0.3 & 20 \\
\hline $30 \%$ S-glass PALF & SGP3030 & 1 & - & 0.3 & 30 \\
\hline $30 \%$ S-glass PALF & SGP3040 & 1 & - & 0.3 & 40 \\
\hline $40 \%$ S-glass PALF & SGP4020 & 1 & - & 0.4 & 20 \\
\hline $40 \%$ S-glass PALF & SGP4030 & 1 & - & 0.4 & 30 \\
\hline $40 \%$ S-glass PALF & SGP4040 & 1 & - & 0.4 & 40 \\
\hline $50 \%$ S-glass PALF & SGP5020 & 1 & - & 0.5 & 20 \\
\hline $50 \%$ S-glass PALF & SGP5030 & 1 & - & 0.5 & 30 \\
\hline $50 \%$ S-glass PALF & SGP5040 & 1 & - & 0.5 & 40 \\
\hline
\end{tabular}

and electrical conductivity, and to forestall electrostatic charging during test assessment. The pictures were examined to research the proper circulation of the natural fibers in the synthetic polymer matrix and their character of connection with one another. The flexural tests were accompanied to find the flexural strength and flexural modulus.
The flexural tests were piloted based on the ASTM standard D790 [35]. The specimen was supported by a support span, and the load was applied to the center by the loading nose, resulting in three-point bending at a set rate. The support span, loading speed, and maximum deflection for the test were the parameters for this test. As per the recommended 
procedure, the ASTM D790 test was accomplished till the point of failure of the specimen. The thermogravimetric analyzer was used to record the variation in the thermal characteristics of the manmade hybrid composites based on their weight loss at different temperatures [36]. It measures the rate of change of material weight for different temperature profiles based on the effects of dehydration, decomposition, and oxidation. The dynamic mechanical investigation was carried out while examining the viscoelastic characteristics at various temperature profiles [37]. This investigation included the application of an oscillatory sprain at various temperatures.

\section{Results and Discussion}

3.1. Flexural Test. The condition of the samples before and after the flexural test is depicted in Figure 2. Three random samples from each fiber composition are presented in Figure 2(b) for better understanding. Flexural test results are presented in Figure 3. The flexural strength of the hybrid composite is nonlinear. It showed an increasing trend from $30 \%$ to $40 \%$, and after $50 \%$ volume fraction, it started to decrease. The flexural strength of the S-glass/PALF hybrid composite was $18 \%$ higher than the S-glass/banana composite [23]. The maximum flexural strength of the SGP40 composite recorded at $20 \mathrm{~cm}, 30 \mathrm{~cm}$, and $40 \mathrm{~cm}$ fiber lengths was $97.5 \mathrm{MPa}$, 103.6 $\mathrm{MPa}$, and $112.3 \mathrm{MPa}$, respectively. As the fiber length of the hybrid composite upsurges, the flexural strength also increases linearly. The percentage strain of the composites decreases with the increase in the volume fraction of the glass fibers. Since the glass fiber is extremely brittle, the flexural strength of the composite increases with an increase in the fiber volume. The maximum flexural strength of the SGB40 composite recorded at $20 \mathrm{~cm}, 30 \mathrm{~cm}$, and $40 \mathrm{~cm}$ fiber lengths were $94.5 \mathrm{MPa}$, $99.8 \mathrm{MPa}$, and $104.5 \mathrm{MPa}$, respectively. The increase in the fiber length of the SGB40 hybrid composite increases the mechanical flexural strength linearly. The greatest flexural strength of the SGBP composite recorded at $20 \mathrm{~cm}, 30 \mathrm{~cm}$, and $40 \mathrm{~cm}$ fiber lengths were $62.5 \mathrm{MPa}, 64.6 \mathrm{MPa}$, and $66.3 \mathrm{MPa}$, respectively. As the fiber length of the SGBP40 hybrid composite increases, the flexural strength also increases linearly. The same kinds of results were obtained and reported by Shen and Gimbun [28]. The reason for this phenomenon was characterized to the insufficient resin. Natural fibers are normally hydrophobic in nature, and they absorb more resin. Hence, insufficient resin led to a decrement in the flexural strength of the polymer hybrid composites, when the fiber volume was increased after $50 \%$. The after-effects of the insufficient resin increased the brittleness, and hence, it started to fail permanently.

The flexural modulus results followed same as that of the flexural strength results, which are shown in Figure 4. It shows an increasing trend from $30 \%$ to $40 \%$, and at $50 \%$ volume fraction, it started to decline. The stiffness of the hybrid composite would be better if the value of the flexural modulus is high. The flexural modulus of the SGP 40 has found to be superior $(8.56 \mathrm{MPa})$ at $40 \mathrm{~cm}$ fiber length. The flexural modulus of the SGBP 40 has been obtained as
$2.76 \mathrm{MPa}$ at $40 \mathrm{~cm}$ fiber length, which is the lowest value ever. Hence, the determined results accredited that the SGP 40 would absorb more forces than the other hybrid composites [27]. The flexural modulus exhibited a decrement with the reduction in the fiber length due to high strain in the material.

3.2. Thermal Test. The thermogravimetric analysis was carried out between $30^{\circ} \mathrm{C}$ and $600^{\circ} \mathrm{C}$ at $10^{\circ} \mathrm{C} / \mathrm{min}$ rate, and its results are presented in Figures 5(a)-5(c). The major degradation for SGB4030 occurred at the temperature between $288^{\circ} \mathrm{C}$ and $451^{\circ} \mathrm{C}$. The peak degradation occurred at $381^{\circ} \mathrm{C}$ temperature. The degradation of the SGP4030 occurred at the temperature between $258^{\circ} \mathrm{C}$ and $426^{\circ} \mathrm{C}$, and the peak happened at $342^{\circ} \mathrm{C}$. The reason for the same is attributed to a different phase of degradation. The first phase of the weight loss occurred from $30^{\circ} \mathrm{C}$ to $100^{\circ} \mathrm{C}$, and it may be due to the moisture evaporation. The subsequent phase occurred between $150^{\circ} \mathrm{C}$ and $430^{\circ} \mathrm{C}$, and it was attributed to the process of decomposition. The next decomposition was hemicellulose decomposition, which started at $250^{\circ} \mathrm{C}$ and ended at $326^{\circ} \mathrm{C}$. In addition, the cellulose decomposition was started. The thermal stability of the cellulose was accredited to their strong chemical structure. Furthermore, lignin decomposition started at $30^{\circ} \mathrm{C}$ and extended till $600^{\circ} \mathrm{C}$. It can be understood that lignin has shown more thermal stability, and hence, it provided the toughness to the natural fibers [38].

The banana and S-glass hybrid composites possess higher thermal degradation temperature, and their mass loss was higher than the PALF and S-glass hybrid composites due to their higher fiber weight $[38,39]$. Hence, SGB 3020, SBP3020, and SGBP 20 have shown lower thermal degradation temperatures. Figure 5 depicts that a decrease in the fiber length would cause a decrease in the mass loss of the hybrid composite. It can be understood that a low rate of decomposition of fiber would be the decline in the mass loss of the hybrid fiber composite.

3.3. Storage Modulus Test. The dynamic mechanical analyzer (V4.5A TA Model) was used to measure the thermal storage modulus. It is preferred because of its comparative effectiveness in measuring the storage modulus $[40,41]$. The hybrid composites were heated from $30^{\circ} \mathrm{C}$ to $200^{\circ} \mathrm{C}$, and their results were plotted as shown in Figures 6(a)-6(c). The results evidenced that owing to the less stiffness of the fiber, a slight variation in the storage modulus for the hybrid polymer composites happened. Furthermore, the storage modulus diminished with temperature for both the natural composites. Hence, the higher fiber volume caused to increase the stiffness of the hybrid composites. However, it demonstrated the waning of stiffness with the increase in temperature [42]. At the PALF fiber proportion of $40 \%$, the least flexural modulus was recorded. It was observed that, if the fiber volume decreases, the storage modulus also decreases due to the mobility of molecules in natural fiber composites. The storage modulus decreased with the decrease in temperature of the glass fiber, and it was compensated with the reinforcement of banana fiber and PALF 

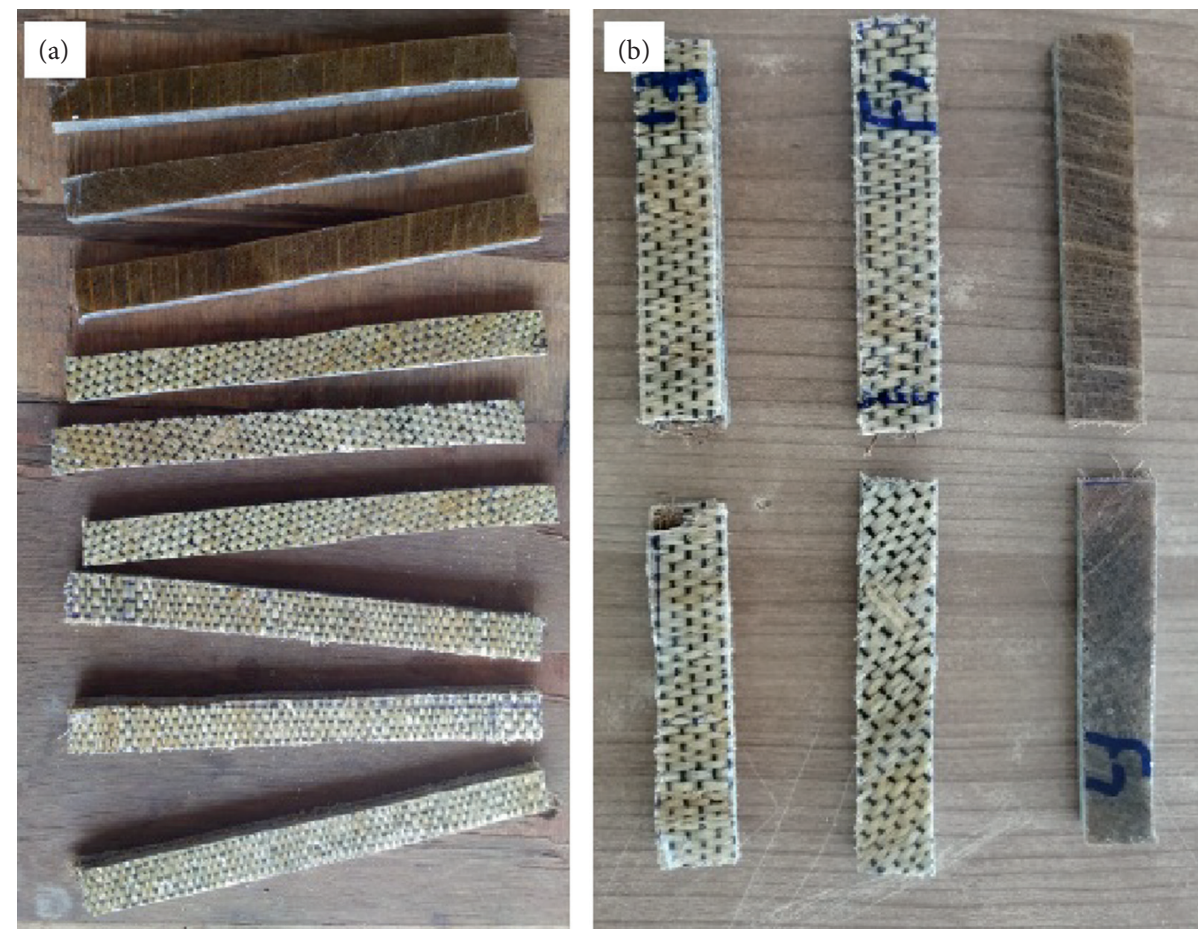

FIgURE 2: Flexural test specimens (a) before and (b) after the test.

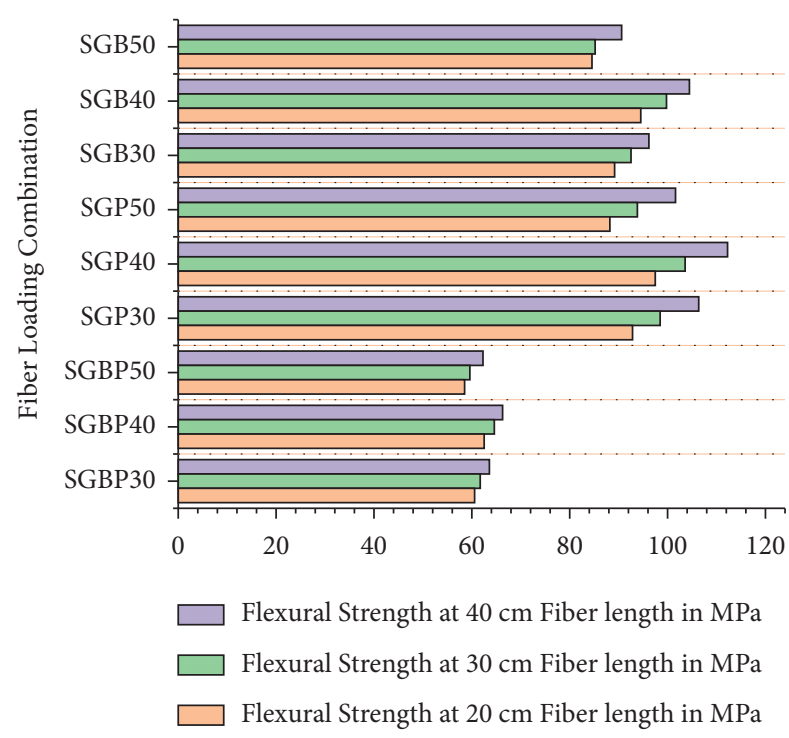

Figure 3: Graphical representation of flexural strength for various samples at different fiber volumes and fiber lengths.

fiber. Because the thermal expansion coefficients of epoxy resin, banana fiber, and PALF fiber are all positive, it became the reason for the changes in mechanical and thermal properties. However, in the absence of residual stress, it has become responsible for a drop in the shear modulus for the increment in the fiber volume and fiber length.

3.4. Comparison. The present work is compared with the previous research work, which was piloted by Mohd Hanafee

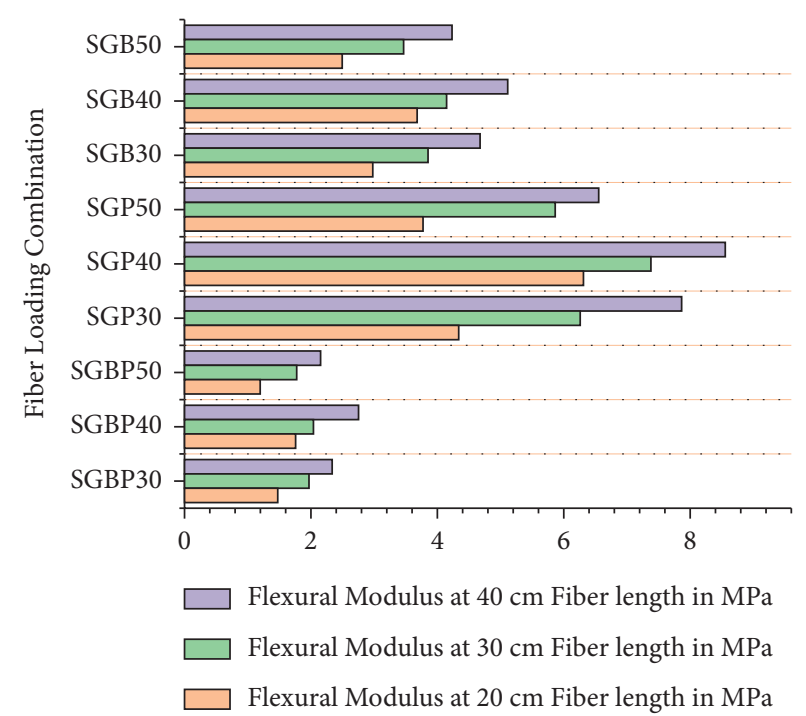

FIGURE 4: Graphical representation of flexural modulus for various samples at different fiber volumes and fiber lengths.

Zin and Nurazzi Norizan [43] for the $40 \%$ fiber volume and $30 \mathrm{~cm}$ fiber length of banana, PALF-reinforced polymer matrix as presented in Table 3. They used E-glass fiber with banana stem and PALF. It is obvious that SGB4030 exhibited a 14.89 percent more flexural strength, 6.85 percent higher flexural strength, 3.95 percent higher loss modulus, 1.77 percent higher storage modulus than [43]. S-glass is a highperformance glass fiber that differs from E-glass fiber principally in terms of silica content. Silica, aluminium, and magnesium oxides are abundantly found in S-glass fiber, and 


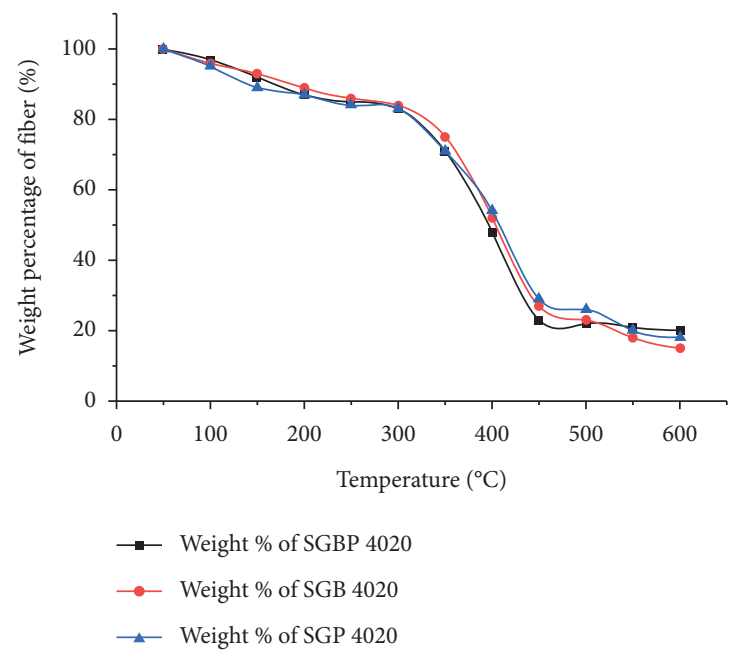

(a)

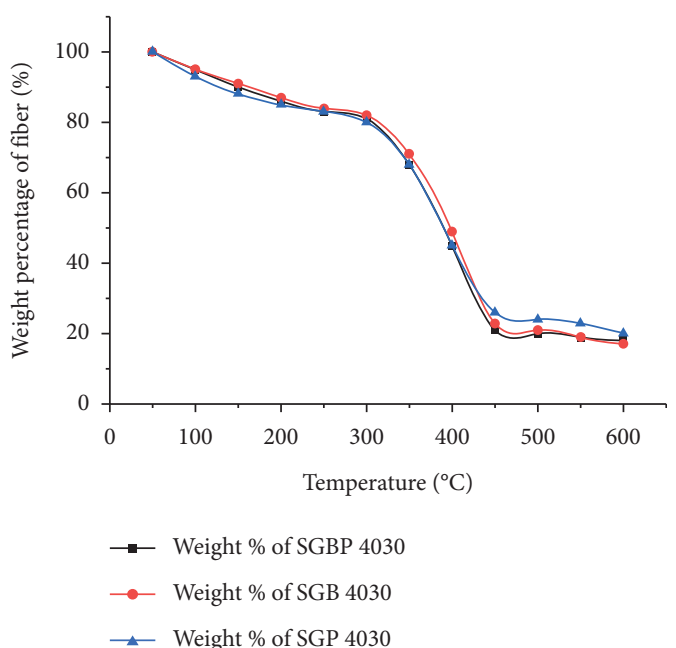

(b)

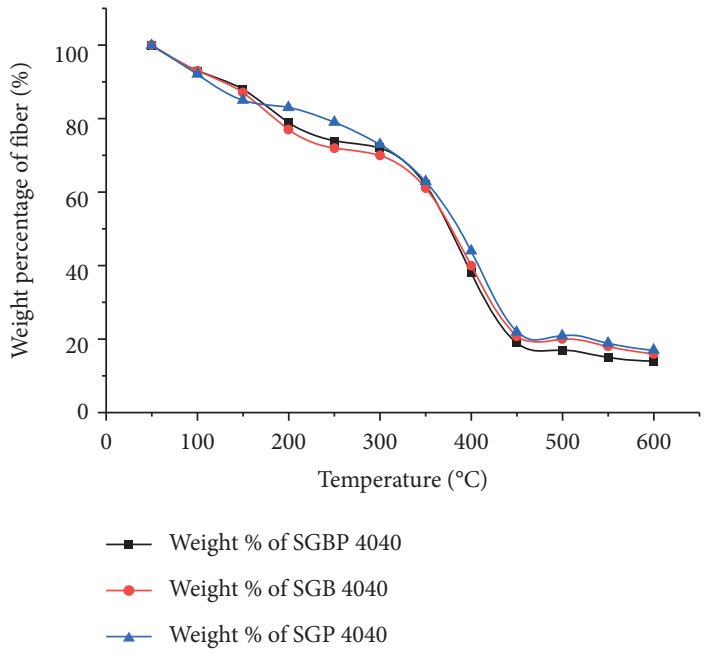

(c)

Figure 5: Graphical representation of weight percentage of $40 \%$ fiber volume sample at (a) $20 \mathrm{~cm}$ fiber length, (b) $30 \mathrm{~cm}$ fiber length, and (c) $40 \mathrm{~cm}$ fiber length.

hence, S-glass fibers are superior in terms of mechanical and thermal properties compared to E-glass fibers.

3.5. Optimization. Hybrid Taguchi Grey relational analysis (HTGRA) was used to find the optimum output parameters from the different input parameters as shown in Table 4. Initially, L27 design of experiments were selected with different combination of fiber type, fiber load, and fiber length. The test specimens were prepared as per the L27 Design of Experiments (Doe), and mechanical and thermal characteristics tests were performed as described in the earlier sections. The output responses (data from Table 5), i.e., flexural strength, flexural modulus, and storage modulus were first converted into a signal to noise ratio based on the following first equation, and the percentage of mass loss was determined by the next equation $[44,45]$ :

$$
\begin{aligned}
& \text { Larger the better }\left(\frac{S}{N}\right)=10 \log \left(\frac{1}{n} \sum_{i=1}^{n} \frac{1}{y i^{2}}\right), \\
& \text { Smaller the better }\left(\frac{S}{N}\right)=10 \log \left(\frac{1}{n} \sum_{i=1}^{n} y i^{2}\right),
\end{aligned}
$$

where " $S / N$ " refers to signal to noise ratio, and " $y i$ " refers to the output response of specific sequence. Then, the data from the $S / N$ ratios were preprocessed using the following equations: 


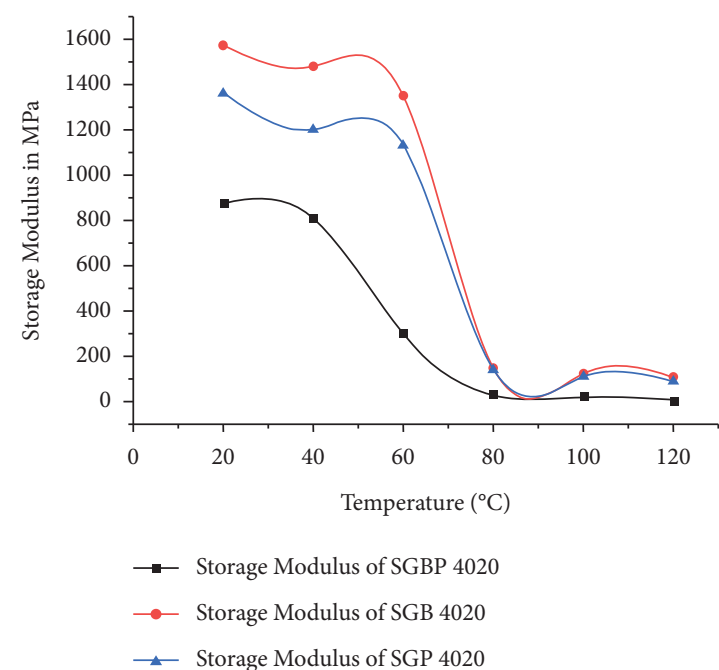

(a)

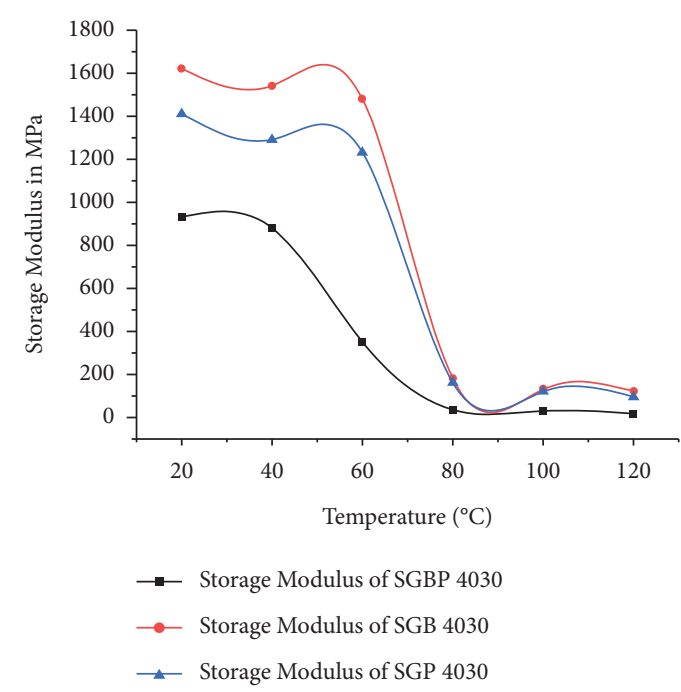

(b)

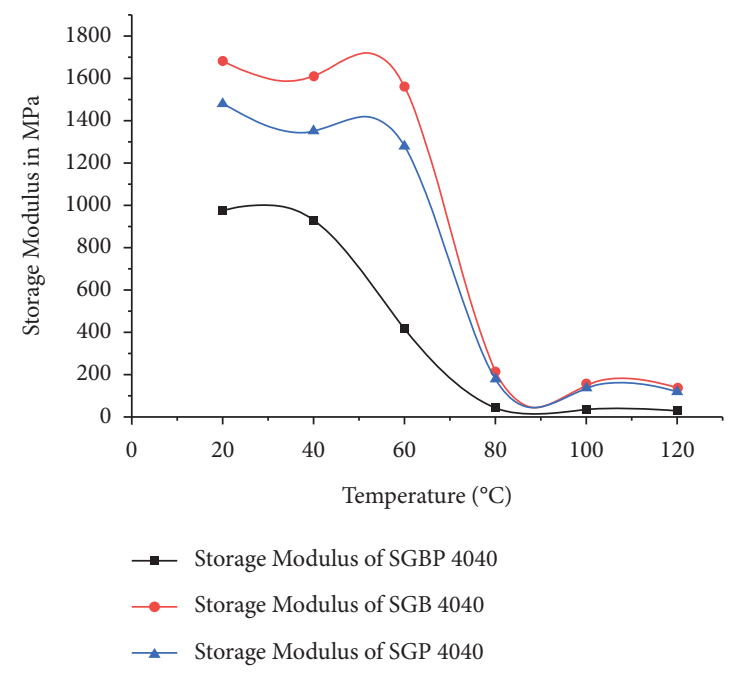

(c)

Figure 6: Graphical representation of storage modulus of sample at $40 \%$ fiber volume sample at (a) $20 \mathrm{~cm}$ fiber length, (b) $30 \mathrm{~cm}$ fiber length, and (c) $40 \mathrm{~cm}$ fiber length.

TABLE 3: Comparison of previous and current research work at $40 \%$ fiber volume and $30 \mathrm{~cm}$ fiber length.

\begin{tabular}{lccccc}
\hline \multirow{2}{*}{ Sl No } & \multirow{2}{*}{ Parameters considered for study } & \multicolumn{2}{c}{ Previous research work [43] } & \multicolumn{2}{c}{ Current research work } \\
& & Banana E-glass & PALF E-glass & Banana S-glass & PALF S-glass \\
\hline 1 & Flexural strength (MPa) & 90.95 & 105.10 & 104.5 & 8.12 \\
2 & Flexural modulus (MPa) & 4.24 & 7.61 & 8.36 \\
3 & Loss modulus & 91.73 & 70.81 & 7.23 & 78.4 \\
4 & Storage modulus (MPa) & 77.94 & 61.16 & 63.58 \\
\hline
\end{tabular}


TABLE 4: Input parameters.

\begin{tabular}{lcccc}
\hline Sl. No & Parameters & Level 1 & Level 2 & Level 3 \\
\hline 1 & Fiber combination & SGBP & SGP & SGB \\
2 & Fiber volume & $30 \%$ & $40 \%$ & $50 \%$ \\
3 & Fiber length & $20 \mathrm{~cm}$ & $30 \mathrm{~cm}$ & $40 \mathrm{~cm}$ \\
\hline
\end{tabular}

TABLE 5: Output responses (samples).

\begin{tabular}{lccccccc}
\hline Sl No & Fiber combination (FC) & $\begin{array}{c}\text { Fiber volume } \\
(\mathrm{FV})(\%)\end{array}$ & $\begin{array}{c}\text { Fiber } \\
\text { length }(\mathrm{FL})(\mathrm{cm})\end{array}$ & $\begin{array}{c}\text { Flexural } \\
\text { strength in MPa }\end{array}$ & $\begin{array}{c}\text { Flexural } \\
\text { modulus in MPa }\end{array}$ & $\begin{array}{c}\text { Total \% of } \\
\text { mass loss }\end{array}$ & $\begin{array}{c}\text { Storage modulus } \\
\text { in MPa }\end{array}$ \\
\hline 1 & SGP & 30 & 20 & 92.8 & 4.35 & 78.72 & 99.31 \\
2 & SGP & 30 & 30 & 98.5 & 6.26 & 83.56 \\
3 & SGP & 30 & 40 & 106.3 & 7.87 & 85.27 \\
4 & SGP & 40 & 20 & 97.5 & 6.32 & 81.46 & 97.43 \\
5 & SGP & 40 & 30 & 103.6 & 7.38 & 85.87 & 68.53 \\
6 & SGP & 40 & 40 & 112.3 & 8.56 & 88.4 & 63.58 \\
7 & SGP & 50 & 20 & 88.2 & 3.78 & 80.56 & 74.35 \\
8 & SGP & 50 & 30 & 93.9 & 5.87 & 84.25 & 71.53 \\
9 & SGP & 50 & 40 & 101.6 & 6.56 & 86.94 & 68.25 \\
\hline
\end{tabular}

Larger the better $(x i)^{*}(k)=\frac{x i^{(o)}(k)-\min x i^{(o)}(k)}{\max x i^{(o)}(k)-\min x i^{(o)}(k)}$,

Smaller the better $(x i)^{*}(k)=\frac{\max x i^{(o)}(k)-x i^{(o)}(k)}{\max x i^{(o)}(k)-\min x i^{(o)}(k)}$,

where $x i^{(o)}(k)$ is an output response value at original sequence, and $\max x i^{(o)}(k)$ is the largest value of sequence, and $\min x i^{(o)}(k)$ is the lowest value of that responses. Equation (4) was used for flexural strength, flexural modulus, and storage modulus as these values should be as large as possible. In addition, equation (5) was used for finding the percentage of mass loss responses as these values should be as small as possible $[46,47]$. Then, the deviation sequence $(€ i$ $(k)$ ) was found using the following equations (ddistinguished coefficient $(€)$ was chosen as 0.5$)$ :

$$
\begin{aligned}
\Delta o i & =\left\|x o^{*}(k)-x i^{*}(k)\right\|, \\
€ i(k) & =\frac{\Delta \min -€ \Delta \max }{\Delta i(k)-€ \Delta \max } .
\end{aligned}
$$

Finally, grey relation grade (GRG) was calculated using equation (7) [48, 49]. GRG was given as input to the software Minitab 19, and then, the optimized parameter plot, regression equation, and $R^{2}$ values were found,

$$
\mathrm{GRG}=\frac{1}{n} \sum_{k=1}^{n} € i(k)
$$

$R^{2}$ value was found to be $95.34 \%$, and the predicted $R^{2}$ value was $89.10 \%$. Hence, the model was found to be valid. Before calculating the $R^{2}$ values, the empirical correlations were created. At a 95\% confidence level, all the coefficients were evaluated for significance. Using the Student's $t$-test,

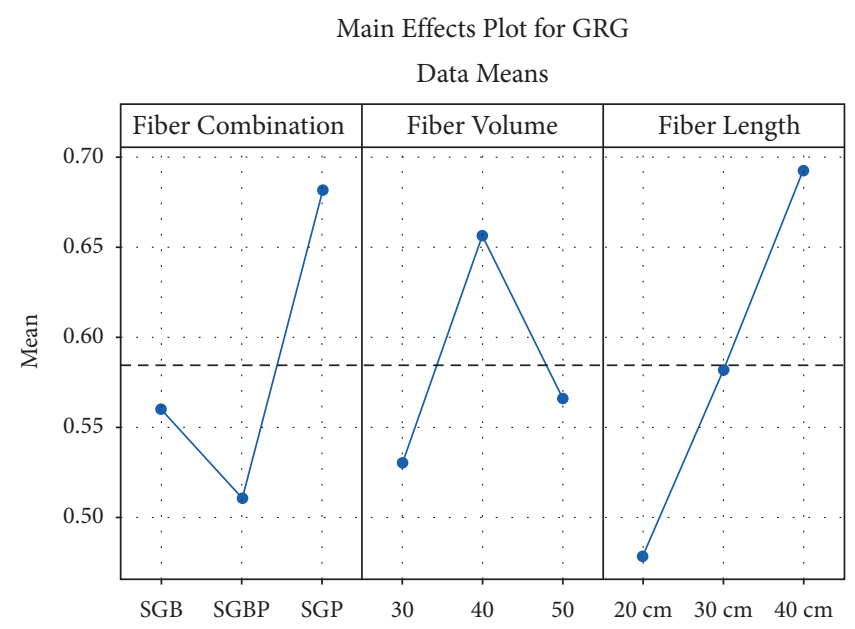

Figure 7: Graphical representation of the main effect plot on output response of input responses.

insignificant coefficients were removed without impacting the correctness of the empirical connections. In order to establish the final empirical relationships, the significant coefficients were taken into account. For all replies, the final developed empirical connections with processing components in the coded form are given in the following regression equation :

$$
\begin{aligned}
\text { Grey Relational Grade }= & \{0.5843-0.2141 X 1-0.0734 X 2 \\
& +0.0975 X 3-0.0541 Y 1 \\
& +0.0724 Y 2-0.0184 Y 3 \\
& -0.1062 Z 1-0.0022 Z 2 \\
& +0.1084 Z 3\}
\end{aligned}
$$

where $X_{1}, X_{2}$, and $X_{3}$ refer to the different levels of fiber combinations, $Y_{1}, Y_{2}$, and $Y_{3}$ are different fiber volume 


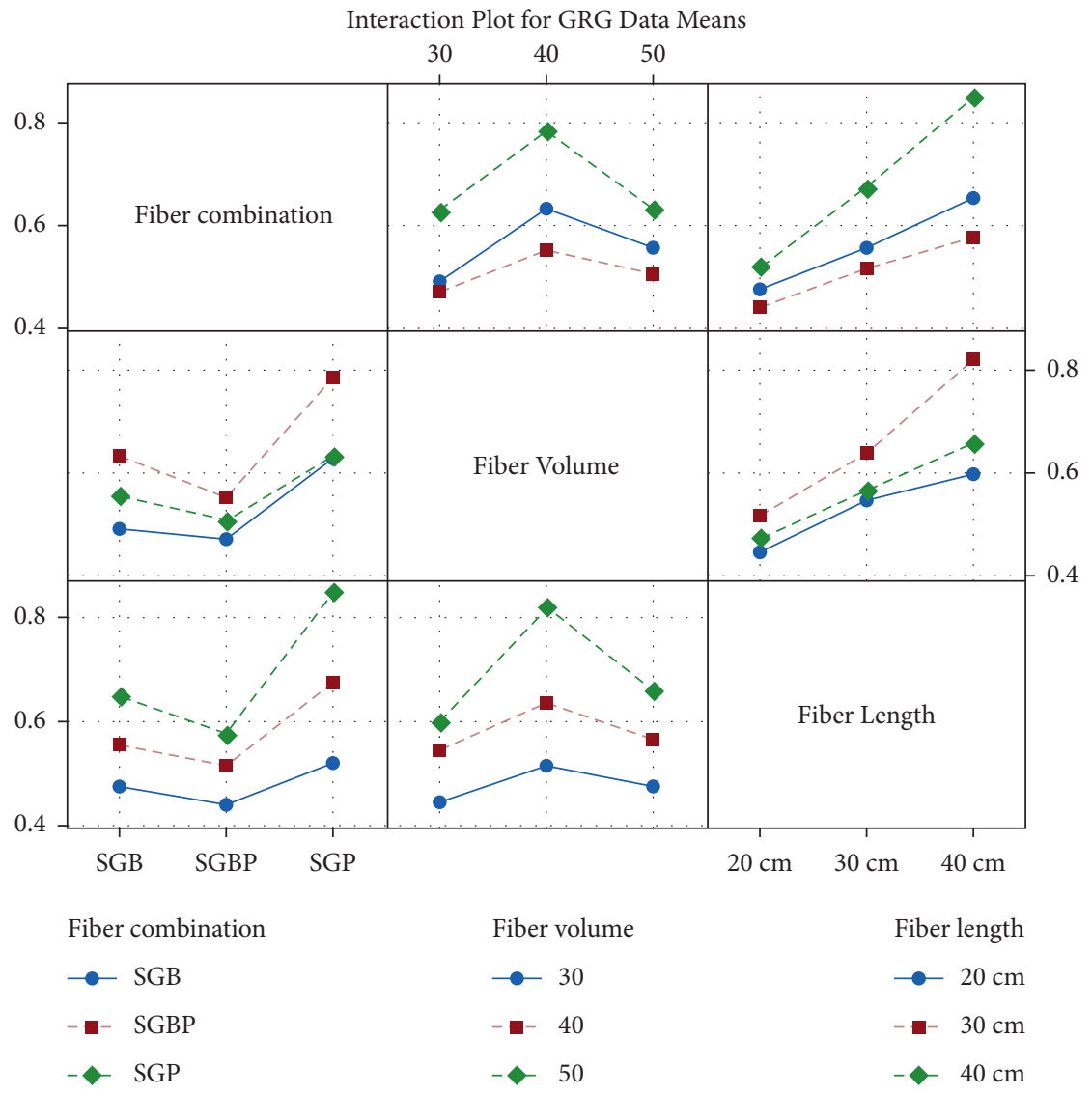

FIGURE 8: Graphical representation of the interaction effect plot on output response of different input responses.

levels, and $Z_{1}, Z_{2}$, and $Z_{3}$ are different levels of fiber length. Based on the GRG values, the main effects and the interaction effects of the input parameters were determined, and the best parameter settings were identified from the main effects plot of grey relational grade response as follows (Figure 7): S-glass PALF fiber combination, $40 \%$ fiber load, and $40 \mathrm{~cm}$ fiber length. According to the interaction effect plot as shown in Figure 8, there is no interaction effect between the input parameters even though S-glass PALF fiber combination, $40 \%$ fiber load, and $40 \mathrm{~cm}$ fiber length combination provides optimum mechanical and thermal properties. The HTGRA technique proposed a set of optimal input parameters, and the tests were carried out once again to validate the results. It yielded the GRG value of 0.796 , and when compared it to the average values of the experimental results, GRG was raised by 0.015 percent during the confirmation test.

\section{Conclusions}

This work deals with the influence of fiber volume and length on mechanical and thermal properties of the polymer hybrid composite. The following inferences are drawn from the critical investigation:

(1) The increment in the fiber volume and fiber length induces the enhancement in the flexural and thermal characteristics of the hybrid composites. After reaching $40 \%$ of the fiber volume, the mentioned characteristics started to decline. Furthermore, an increment in the fiber length always has positive effects on the mechanical and thermal properties.

(2) Based on the assessment of the mechanical properties, SGP4030 exhibited better flexural properties, i.e., flexural modulus and flexural strength of 8.6 $\mathrm{MPa}$ and $112.3 \mathrm{MPa}$, respectively. On the other hand, SGBP3020 registered a $6 \mathrm{MPa}$ and $4.35 \mathrm{MPa}$ of flexural strength and flexural modulus, respectively, which are the lowest values compared to other combinations. However, the flexural strength of SGB4030 was observed as $14.89 \%$ higher than the SEB4030. Similarly, the flexural strength of SGP4030 was $6.85 \%$ higher than the SEB4030.

(3) The assessment of the thermal properties revealed that SGB4020 and SGP4020 exhibited a low mass loss, and SGB4030 presented the higher storage modulus. The storage modulus of SGB4030 was perceived as 3.95\% higher than the SEB4030. Likewise, the storage modulus of SGP4030 was $1.77 \%$ higher than the SEB4030.

(4) Hybrid Taguchi GRA techniques suggested that PALF-reinforced S-glass fiber with a $40 \%$ fiber volume and $40 \mathrm{~cm}$ fiber length provides the optimum mechanical and thermal properties compared to other combinations. 


\section{Data Availability}

The data used to support the findings of this study are included within the article.

\section{Conflicts of Interest}

The authors declare that there are no conflicts of interest regarding the publication of this paper.

\section{References}

[1] S. Alsubari, M. Y. M. Zuhri, S. M. Sapuan, M. R. Ishak, R. A. Ilyas, and M. R. M. Asyraf, "Potential of natural fiber reinforced polymer composites in sandwich structures: a review on its mechanical properties," Polymers, vol. 13, no. 3 , p. 423, 2021.

[2] S.-K. Yeh, C.-R. Hu, M. B. Rizkiana, and C.-H. Kuo, "Effect of fiber size, cyclic moisture absorption and fungal decay on the durability of natural fiber composites," Construction and Building Materials, vol. 286, 2021.

[3] S. Sekar, S. Suresh Kumar, S. Vigneshwaran, and G. Velmurugan, "Evaluation of mechanical and water absorption behavior of natural fiber-reinforced hybrid biocomposites," Journal of Natural Fibers, 2020.

[4] A. C. Manalo, E. Wani, N. A. Zukarnain, W. Karunasena, and K. T. Lau, "Effects of alkali treatment and elevated temperature on the mechanical properties of bamboo fibre-polyester composites," Composites Part B: Engineering, vol. 2015, no. 80, pp. 73-83.

[5] K. Makhijani, R. Kumar, and S. K. Sharma, "Biodegradability of blended polymers: a comparison of various properties," Critical Reviews in Environmental Science and Technology, vol. 45, no. 16, pp. 1801-1825.

[6] H. A. McKenna, J. W. S. Hearle, and N. O'Hear, Handbook of Fibre Rope Technology, Woodhead Publishing in Textiles, Cambridge, England, 2004.

[7] G. Basu, A. N. Roy, and A. N. Roy, "Blending of jute with different natural fibres blending ofjute with different natural fibres," Journal of Natural Fibers, vol. 4, no. 4, 2008.

[8] Y. Gowda, T. Girirajappa, S. M Rangappa, J. Parasmeswaranpillai, and S. SiengChen, "Natural fiber as a sustainable and renewable energy development of eco friendly composites: a Comprehensive Review," Front matter, vol. 6, pp. 1-14, 2019.

[9] M. R. Abdul Karim, D. Thair, E. U Haq, A. Hussain, and M. S. Malik, "Natural fiber as a promising environmental friendly reinforcements for polymer composites," Polymer Composites, vol. 29, pp. 1-24, 2020.

[10] F. T. Sheng and J. Gimbun, "Strengthening performance of PALF-epoxy composite plate on reinforced concrete beams," IOP Conference Series: Materials Science and Engineering, pp. 1-9, 2017.

[11] J. Jain, S. Jain, and S. Sinha, "Characterization and thermal kinetic analysis of pineapple leaf fibers and their reinforcement in epoxy," Journal of Elastomers and Plastics, vol. 51, no. 3, pp. 1-12, 2018.

[12] R. Chollakup, H. Askanian, and F. Delor-Jestin, "Initial properties and ageing behaviour of pineapple leaf and palm fibre as reinforcement for poly propylene," $J$ thermoplastic Compos Mater, vol. 30, no. 2, pp. 174-195, 2017.

[13] Y. F. Shih, W. C. Chang, W. C. Liu, C. C. Lee, C. S. Kuan, and Y. H. Yu, "Pineapple leaf/recycled disposable chopstick hybrid fiber-reinforced biodegradable composites," Journal of
Taiwan, Institute of Chemical Engineering, vol. 45, pp. 20392046, 2014.

[14] M. Asim, M. Jawaid, K. Abdan, M. I. Ridzwan, M. R. Ishak, and O. Y. Alothman, "Effect of hybridization on the mechanical properties of pineapple leaf fibre/kenaf phenolic hybrid composites," Journal of Renew Mater, vol. 6, 2017.

[15] S. Nur, R. Ramli, and U. Teknikal, "The effect of alkaline treatment and fiber length on pineapple leaf fiber reinforced poly lactic acid biocomposite," Journal of Teknol, vol. 79, pp. 111-125, 2017.

[16] I. S. Aji, E. S. Zainudin, A. Khalina, S. M. Sapuan, and M. D. Khairul, "Studying the effect of fiber size and fiber loading on the mechanical properties of hybridized kenaf/ PALF-reinforced HDPE composite," Journal of Reinforced Plastics and Composites, vol. 30, pp. 546-553, 2011.

[17] S. Luo and A. N. Netravali, "Mechanical and thermal properties of environment-friendly "green" composites made from pineapple leaf fibers and poly (hydroxy butyrate-co-valerate) resin," Polymer Composites, vol. 20, no. 3, pp. 367-378, 1999.

[18] R. Chollakup, R. Tantatherdtam, S. Ujjin, and K. Sriroth, "Pineapple leaf fibre reinforced thermoplastic composites: effects of fibre length and fibre content on their characteristics," Jornal of Applied Polymer Science, vol. 119, no. 4, 1952.

[19] N. Lopattananon, K. Panawarangkul, K. Sahakaro, and B. Ellis, "Performance of pine apple leaf fiber-natural rubber composites: the effect of fiber surface treatments," Journal of Applied Polymer Science, vol. 102, no. 2, pp. 1974-1984.

[20] N. Graupner, G. Ziegmann, F. Wilde, F. Beckmann, and J. Müssig, "Procedural influences on compression and injection moulded cellulose fibre-reinforced polylactide (PLA) composites: influence of fibre loading, fibre length, fibre orientation and voids," Compos Applied Science Manuf, vol. 81, pp. 158-171, 2016.

[21] M. F. M. Alkbir, S. M. Sapuan, A. A. Nuraini, and M. R. Ishak, Fibre Properties and Crash Worthiness Parameters of Natural Fibre-Reinforced Composite Structure:, Elsevier, Amsterdam, Netherlands, 2016.

[22] M. F. Zainuddin, S. Rosnah, M. M. Noriznan, and I. Dahlan, "Effect of moisture content on physical properties of animal feed pellets from pineapple plant waste," Agriculture and Agriculture Science Procedia, vol. 2, pp. 224-230, 2014.

[23] K. L. Pickering, M. G. A. Efendy, and T. M. Le, "A review of recent developments in natural fibre composites and their mechanical performance," Composite Applied Science Manufacturing, vol. 83, pp. 98-112, 2016.

[24] Y. F. Shih, J. X. Cai, C. S. Kuan, and C. F. Hsieh, "Plant fibers and wasted fiber/epoxy green composites," Composites Part B: Engineering, vol. 43, no. 7, pp. 2817-2821, 2012.

[25] N. Kengkhetkit and T. Amornsakchai, "Utilisation of pineapple leaf waste for plastic reinforcement: 1. A novel extraction method for short pineapple leaf fiber," Industrial Crops and Products, vol. 40, no. 1, pp. 55-61, 2012.

[26] A. Kalapakdee and T. Amornsakchai, "Mechanical properties of preferentially aligned short pineapple leaf fiber reinforced thermoplastic elastomeric: effects of fiber content and matrix orientation," Polymer Testing, vol. 37, pp. 36-44, 2014.

[27] A. N. Kasim, M. Z. Selamat, N. Aznan et al., "Effect of pineapple leaf fiber loading on the mechanical properties of pine apple leaf fiber - polypropylene composite," Journal of Teknol, vol. 77, no. 21, pp. 117-123, 2015.

[28] F. T. Sheng and J. Gimbun, "Strengthening performance of PALF-epoxy composite plate on reinforced concrete beams," IOP conference series: materials science and engineering, vol. 318, 2017. 
[29] K. Z. M. A. Motaleb, M. d. Shariful Islam, and M. B. Hoque, "Improvement of physic-mechanical properties of pineapple leaf fiber reinforced composite," International Journal of Biomater, vol. 2018, Article ID 7384360, 7 pages, 2018.

[30] W. Liu, M. Misra, P. Askeland, L. T. Drzal, and A. K. Mohanty, "“Green” composites from soy based plastic and pineapple leaf fiber: fabrication and properties evaluation," Polymer, vol. 46, no. 8, pp. 2710-2721, 2005.

[31] S. Kaewpirom and C. Worrarat, "Preparation and properties of pineapple leaf fiber reinforced poly (lactic acid) green composites," Fibers and Polymers, vol. 15, no. 7, pp. 1469-1477, 2014.

[32] A. Kalambettu, A. Damodaran, S. Dharmalingam, A. Kalambettu, and D. S. DamodaranA, "Evaluation of biodegradation of pineapple leaf fiber reinforced PVA composites," Journal of Natural Fibers, vol. 12, no. 1, pp. 39-51, 2015.

[33] W. Smitthipong, R. Tantatherdtam, and R. Chollakup, "Effect of pineapple leaf fiber-reinforced thermoplastic starch/pol$\mathrm{y}$ (lactic acid) green composite: mechanical, viscosity, and water resistance properties," Journal of Thermoplastic Composite Materials, 2015.

[34] D. Mathivanan, H. Norfazilah, J. P. Siregar, M. R. M. Rejab, D. Bachtiar, and T. Cionita, "The study of mechanical properties of pineapple leaf fibre reinforced tapioca based bio plastic resin composite," MATEC Web Conferences, vol. 74, pp. 5-8, 2016.

[35] N. M. Barkoula, B. Alcock, N. O. Cabrera, and T. Peijs, "Poly(lactic acid) composites reinforced with leaf fibers from ornamental variety of hybrid pineapple (Potyra)," Polymers and Polymer Composites, vol. 16, no. 2, pp. 101-113, 2017.

[36] M. K. Gupta and R. K. Srivastava, "Mechanical properties of hybrid fibers-reinforced polymer composite: a review," Taylor \& Francis, vol. 55, 2016.

[37] S. Rathika, K. Palanikumar, P. S. S. Raghavan, S. Rathika, K. Palanikumar, and P. S. R. ., "Physical performance of sisalPALF-banana/glass fiber reinforced polyester hybrid composites," Asian Journal of Chemistry, vol. 2, no. 4, pp. 21-36, 2012.

[38] C. Ngaowthong, K. Mongkut, T. Nor, and R. View, "Effect of Dielectric Barrier Discharge Plasma Surface Treatment on the Properties of Pineapple Leaf Fiber Reinforced Poly( La," Materials Science Forum, vol. 862, 2016.

[39] S. H. Sheikh MdFadzullah, Z. Mustafa, S. N. R. Ramli, Q. Yaacob, and Y.A. F. Mohamed, "Preliminary study on the mechanical properties of continuous long pineapple leaf fibre reinforced PLA bio composites," Key Engineering Materials, vol. 694, pp. pp18-22, 2016.

[40] T. T. Nagarajan, A. S. Babu, K. Palanivelu, and S. K. Nayak, "Mechanical and thermal properties of PALF reinforced epoxy composites," Macromolecular Symposia, vol. 361, no. 1, pp. 57-63, 2016.

[41] P. Suwanruji, T. Tuechart, W. Smitthipong, and R. Chollakup, "Modification of pine apple leaf fiber surfaces with silane and isocyanate for reinforcing thermoplastic," Journal of Thermoplastic Composite Materials, vol. 30, no. 10, pp. 1344-1360, 2017.

[42] D. Puglia, J. Biagiotti, and J. M. Kenny, "A review on natural fibre-based composites - Part II: application of natural reinforcements in composite materials for automotive industry," Journal of Natural Fibers, vol. 1, 2008.

[43] K. A. Mohd Hanafee Zin and M. Nurazzi Norizan, "The effect of different fiber loading on flexural and thermal properties of banana/pine apple leaf (PALF)/glass hybrid composite,"
Structural Health Monitoring of Biocomposites, Fibre-Reinforced Composites and Hybrid Composites, pp. 1-17, 2019.

[44] R. Viswanathan, S. Ramesh, S. Maniraj, and V. Subburam, "Measurement and multi-response optimization of turning parameters for magnesium alloy using hybrid combination of Taguchi-GRA-PCA technique," Measurement, vol. 159, Article ID 107800, 2020.

[45] T. K. Mulenga, A. U. Ude, and C. Vivekanandhan, "Techniques for modelling and optimizing the mechanical properties of natural fiber composites: a review," Fibers, vol. 9, p. 6, 2021.

[46] O. Smith Onyekwere, M. H. Oladeinde, and R. O. Edokpiab, "Multi-Response optimization of bamboo fiber reinforced unsaturated polyester composites using hybrid Taguchi - grey relational analysis method," Journal of Industrial and Production Engineering, pp. 98-107, 2020.

[47] N. M. Mehat, S. Kamaruddin, and Abdul Rahim Othman, "Hybrid integration of Taguchi parametric design, grey relational analysis, and principal component analysis optimization for plastic gear production," Chinese Journal of Engineering, vol. 2014, Article ID 351206, 11 pages, 2014.

[48] B. Singaravel, S. Deva Prasad, K. Chandra Shekar, K. Mangapathi Rao, and G. Gowtham Reddy, "Optimization of process parameters using hybrid Taguchi and VIKOR method in electrical discharge machining process," in Advanced Engineering Optimization through Intelligent Techniques Computing, vol 949, R. Venkata Rao and J. Taler, Eds., Advances in Intelligent Systems and Springer, New York, NY, USA, 2020.

[49] T.-P. Dao, "Multiresponse optimization of a compliant guiding mechanism using hybrid taguchi-grey based fuzzy logic approach," Mathematical Problems in Engineering, vol. 2016, Article ID 386893, 17 pages, 2016. 